\title{
Determinación de la calidad del agua del manantial del fundo San Bernardo del distrito de Chiguata para consumo humano
}

\author{
Determination of the quality of spring water from the Saint Bernard \\ district of Chiguata for human consumption \\ Recibido: agosto 20 de 2019 | Revisado: setiembre 12 de 2019 | Aceptado: noviembre 15 de 2019
}

\author{
Luis Avit Medina Quispe ${ }^{I}$ \\ Matilde Yupanqui Mendoza ${ }^{\mathrm{I}}$
}

\begin{abstract}
Resumen
Evaluamos la calidad del agua de manantial del fundo San Bernardo de Chiguata para determinar si podría ser utilizada para consumo humano. Se realizaron ocho muestreos, durante las cuatro estaciones del año. La toma de muestra fue puntual, según el protocolo de monitoreo de los recursos hídricos de la Autoridad Nacional del Agua- DGCRH utilizando métodos de ensayos normalizado por la EPA. Se determinaron parámetros físicos, químicos, aniones y cationes, elementos ecotóxicos y parámetros microbiológicos (coliformes totales y fecales). Los resultados fueron comparados con el DSN031-2010 y la NTP 214.024-1988 (revisada y actualizada Resolución Directoral $N^{\circ}$ 031-2017-INACAL/DN (2017-09-05). Se concluyó que la dureza total, solidos disueltos y la conductividad eléctrica, los iones $\mathrm{As}^{3+}, \mathrm{F}^{-}, \mathrm{Cl}^{-}$y el boro; presentan valores que exceden a lo indicado en la norma. Según Rigola esta agua subterránea es muy dura, pertenece a una clase de tipo mineral por el grado de mineralización según el residuo seco a $180^{\circ} \mathrm{C}$.
\end{abstract}

Palabras clave: manantial, calidad del agua, mineralización

\begin{abstract}
In the present work the quality of the spring water of the San Bernardo de Chiguata farm was evaluated to determine if it could be used for human consumption. Eight samples were taken during the four seasons of the year. The sampling was timely, according to the water resources monitoring protocol of the National Water Authority-DGCRH using EPA standardized test methods. Were determinated Physical and Chemical, anion and cation parameters, eco-toxic elements and microbiological parameters (total and fecal coliforms). The results were compared with $\mathrm{DSN}^{\circ}$ 031-2010 and NTP 214.024-1988 (revised and updated Directive Resolution No. 031- 2017-INACAL / DN (2017-09-05). It was concluded that total hardness, dissolved solids and electrical conductivity, As3 ,$+ \mathrm{F}-, \mathrm{Cl}-$ and boron ions; they present values that exceed what is indicated in the standard. According to Rigola, this groundwater is very hard, it belongs to a class of mineral type, due to the degree of mineralization, according to the dry residue at $180{ }^{\circ} \mathrm{C}$.
\end{abstract}

Key words: spring, water quality, mineralization
Departamento Académico de Química. Universidad Nacional de San Agustín de Arequipa Perú myupanqui1@unsa.edu.pe

(C) Los autores. Este artículo es publicado por la Revista Campus de la Facultad de Ingeniería y Arquitectura de la Universidad de San Martín de Porres. Este artículo se distribuye en los términos de la Licencia Creative Commons Atribución No-comercial - Compartir-Igual 4.0 Internacional (https://creativecommons.org/licenses/ CC-BY), que permite el uso no comercial, distribución y reproducción en cualquier medio siempre que la obra original sea debidamente citada. Para uso comercial contactar a: revistacampus@usmp.pe. 


\section{Introducción}

El agua dulce es un recurso natural que se debe cuidar y preservar. Este es el caso del agua del fundo San Bernardo ubicado en el distrito de Chiguata el cual es consumida por más de 150 pobladores, directamente sin ningún tratamiento, por esto fue necesario caracterizar esta agua, en vista que no existe ningún reporte de monitoreo medio ambiental que incluya el análisis físico, químico, microbiológico y elementos ecotóxicos, razón por la cual fue de suma necesidad, realizar un estudio que permita determinar la calidad del agua de dicho fundo para darle un correcto uso, que conlleva a cuidar y utilizarla adecuadamente. Sin embargo, existe una gran cantidad de personas que desconocen la importancia de mantener el agua libre de contaminación.

Yupanqui (2006) indica que Teodoro Haenke (1976) realizó los primeros estudios sobre las aguas termales de Yura, y de las aguas minerales subterráneas de Jesús que pertenecen al distrito de Paucarpata y de las aguas minerales de Socosani del distrito de Yura, en la actualidad, es utilizada para bebida; ambas en el departamento de Arequipa. También indica que, en 1827 Mariano de Rivero y Ustaríz, determinó la composición química de las aguas de Yura y los usos de estas aguas con fines curativos. Históricamente, Antonio Raymondi en 1882 publicó estudios de los análisis fisicoquímicos sobre las aguas minerales del Perú, para cuyo fin recorrió casi todo el territorio nacional. (Yupanqui (2006) y Masías (2007) realizaron un estudio geoquímico de las fuentes termales y frías asociadas al volcán Misti. Entre ellas, del agua del Ojo del Milagro. Ubicado en el distrito de Characato a $2581 \mathrm{msnm}$, el acceso se realiza por la carretera que une la plaza de Characato con el anexo de Yanayaco, un desvío hacia el Ojo del Milagro. Es una fuente conformada por dos manantiales, uno grande y está un poco más alto que el otro, de estas fuentes aflora una gran cantidad de agua para el consumo humano, la agricultura y uso recreacional.

Zúñiga (2013) caracterizó el agua subterránea de la zona del Ojo del Milagro del distrito de Characato-Arequipa en base a los resultados obtenidos, concluyó que el $\mathrm{As}^{3+}$ está en una concentración de $0,023 \mathrm{mg} / \mathrm{L}$, el $\mathrm{Pb}^{2+}$ en $0,017 \mathrm{mg} / \mathrm{L}$, estos dos parámetros sobrepasan el LMP del DSN031-2010. Se encontró boro en una concentración de 1,050 mg/L.

Por todo lo expuesto, el objetivo del presente trabajo fue determinar la calidad del agua del manantial del fundo San Bernardo- distrito de Chiguata, utilizada para consumo humano. Para este proceso se establecieron tres estrategias de estudio, en la primera se determinaron los parámetros físicos y químicos del agua del fundo San Bernardo durante las cuatro estaciones (verano, otoño, invierno y primavera del ańo 2014); en la segunda, se cuantificaron los elementos ecotóxicos arsénico, bario, cadmio, cromo, plomo, mercurio $y$ selenio. Finalmente, se determinaron los parámetros microbiológicos: coliformes totales y coliformes fecales. Todos los parámetros antes indicados fueron evaluados de acuerdo a DS $\mathrm{N}^{\circ}$ 0312010. El agua del fundo San Bernardo actualmente, es utilizada para riego de alfalfa, tunas, tubérculos y bebida de animales; también se usa para el consumo humano, pero sin tener conocimiento de la calidad del agua. Siendo el aporte de 
este trabajo establecer una línea base de la composición química y microbiológica del agua del Fundo San Bernardo.

\section{Método}

Los análisis se realizaron utilizando los materiales y equipos disponibles en las instalaciones de BHIOS LABORATORIOS. El ámbito de estudio comprende el Fundo San Bernardo que está situado en el distrito de Chiguata provincia y departamento de Arequipa, en las siguientes coordenadas (GPS) 19k 237513 este, UTM 8184750 norte,con una altura promedio de $2680 \mathrm{~ms}$. n. $\mathrm{m}$. Está ubicado al oeste del distrito de Chiguata a unos $12 \mathrm{Km}$ de la ciudad de Arequipa. Tal como puede observar en el mapa adjunto (Figura1).

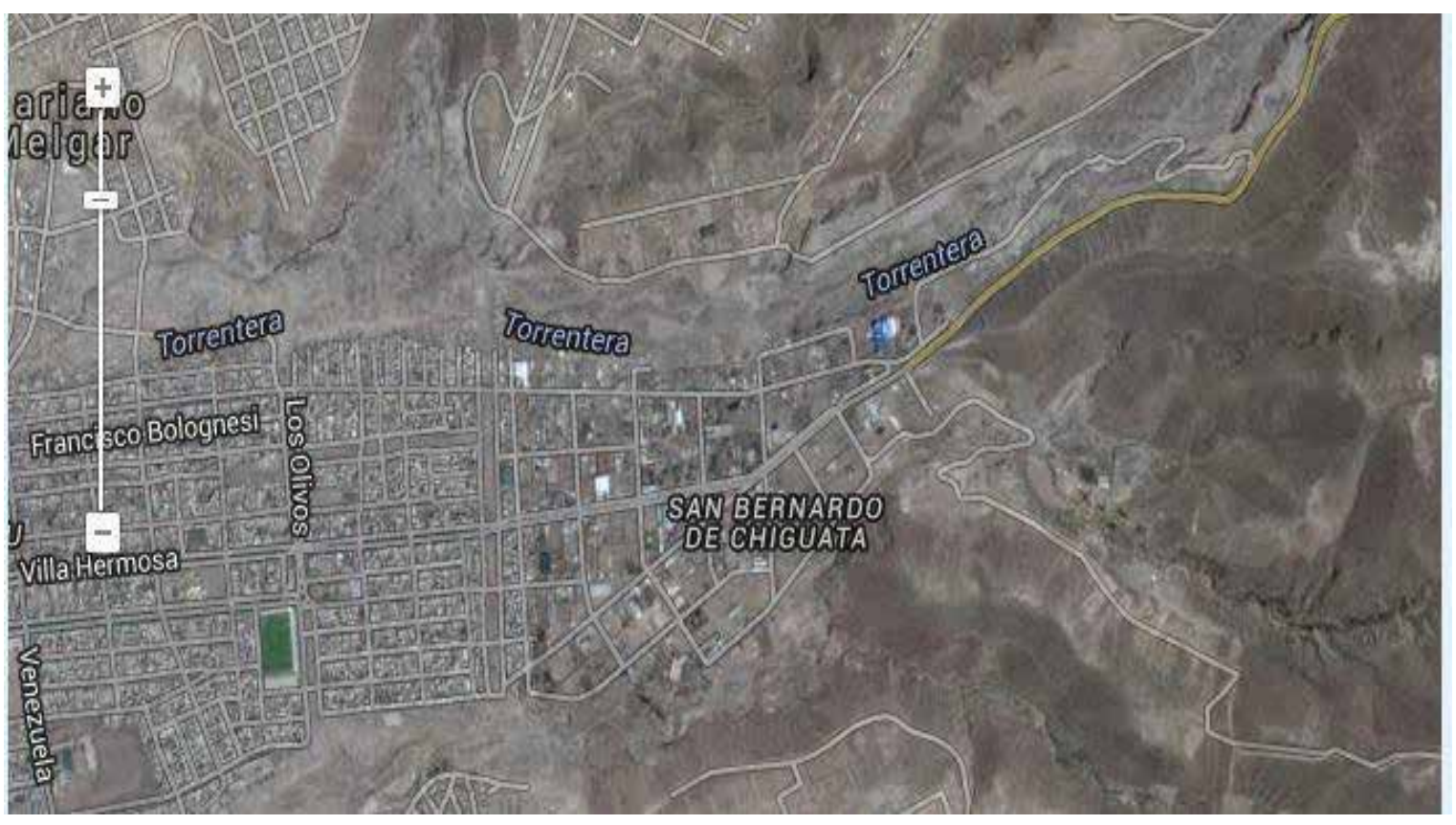

Figura1. Fundo San Bernardo. Fuente: https:/earth.google.es/

Se realizaron ocho salidas al campo y efectuaron ocho muestreos. Para colectar las muestras se utilizaron envases de plástico de $1 \mathrm{~L}$ de capacidad debidamente etiquetados, lavados previamente con agua destilada y cebados tres veces con la misma agua en cada muestreo. Se describió las características del entorno a la fuente de agua (presencia de residuos, vegetación acuática, actividades humanas, presencia de animales y otros factores que modifican las características naturales del agua. Se identificó los puntos de muestreo e ingresó la información en el registro de la cadena custodia de las muestras. El transporte de las mismas fue en cooler hasta su llegada al laboratorio; se tomaron fotografías del punto de monitoreo.

En cuanto a los métodos utilizados, en la Tabla 1 se resumen los métodos analíticos utilizados en la determinación de cada uno de los parámetros analizados en las muestras del agua de manantial del fundo San Bernardo; se siguió el procedimiento: Standard Methods APHA-AWWA-WEF, 2000 
Tabla 1

Métodos empleados para el análisis de parámetros del agua del fundo San Bernardo

\begin{tabular}{|c|c|}
\hline Parámetros Físicos & Métodos Analíticos-empleados \\
\hline Temperatura & Instrumental- \\
\hline Olor & $\begin{array}{l}\text { Standard Methods for the examination of water and wasterwater } \\
\text { Method } 2150-\mathrm{B} \text {. Thershold Odor Test. }\end{array}$ \\
\hline Sabor & $\begin{array}{l}\text { Standard Methods for the examination of waterand wasterwater } \\
\text { Method 2160-B.Flavor } \\
\text { Test. }\end{array}$ \\
\hline Color & Turbidimétrico \\
\hline Turbidez & Turbidimétrico \\
\hline Sólidos disueltos totales & SMWW2540-C \\
\hline \multicolumn{2}{|l|}{ Parámetros Químicos } \\
\hline $\mathrm{pH}$ & Potenciómetro \\
\hline Conductividad Eléctrica & Conductímetro \\
\hline Cloruros & SMWW4500Cl-E \\
\hline Dureza total & NTP 214.018 \\
\hline \multicolumn{2}{|l|}{ Parámetros Fisicoquímicos } \\
\hline Sulfatos & SMWW4500-SO42- E \\
\hline Nitratos & WAH HACH8039 \\
\hline Nitritos & WAH HACH8507 \\
\hline Flúor & WAH HACH8029 \\
\hline Fósforo & WAH HACH8048 \\
\hline Boro & WAH HACH8015 \\
\hline \multicolumn{2}{|l|}{ Nitrógeno amoniacal } \\
\hline \multicolumn{2}{|l|}{ Arsénico } \\
\hline Metales & Absorción Atómica y Análisis por ICP-Masa \\
\hline \multicolumn{2}{|l|}{ Parámetros Microbiológicos } \\
\hline Bacterias coliformes totales & Microbiológico (NMP/100 mL) \\
\hline Bacterias coliformes fecales & Microbiológico (NMP/100 mL) \\
\hline
\end{tabular}

Fuente: BHIOS LABORATORIOS. Protocolo de análisis.2014

\section{Resultados y Discusión}

Para evaluar la calidad del agua del manantial del fundo San Bernardo se realizaron ocho muestreos, dos muestreos por estación del año para tener mayor visión de la variabilidad de los parámetros evaluados. Los resultados obtenidos fueron referenciados a los valores dados en la Norma DSN031-2010-SA a fin de saber si es apta para consumo humano. En la Tabla 2 se observan los resultados de análisis de campo de las diferentes estaciones del año durante los ocho muestreos del agua de manantial del fundo San Bernardo. 
Tabla 2

Resultados de campo del agua de manantial del fundo San Bernardo

\begin{tabular}{lccc}
\hline $\begin{array}{c}\text { Parámetro } \\
\begin{array}{c}\text { Muestreos durante } \\
\text { el ańo 2014 }\end{array}\end{array}$ & $\mathbf{p H}$ & Temperatura $\left({ }^{\circ} \mathbf{C}\right)$ & $\begin{array}{c}\text { Conductividad } \\
(\mathbf{u S} / \mathbf{c m})\end{array}$ \\
\hline Enero & 7,2 & 21,1 & 1773 \\
Febrero & 7,25 & 20,0 & 1778 \\
Marzo & 7,3 & 19,9 & 1763 \\
Mayo & 6,71 & 16,8 & 1756 \\
Junio & 7,45 & 20,5 & 1773 \\
Julio & 7,38 & 20,4 & 1746 \\
Setiembre & 7,06 & 19,8 & 1739 \\
Octubre & 6,92 & 17,4 & 1752 \\
\hline
\end{tabular}

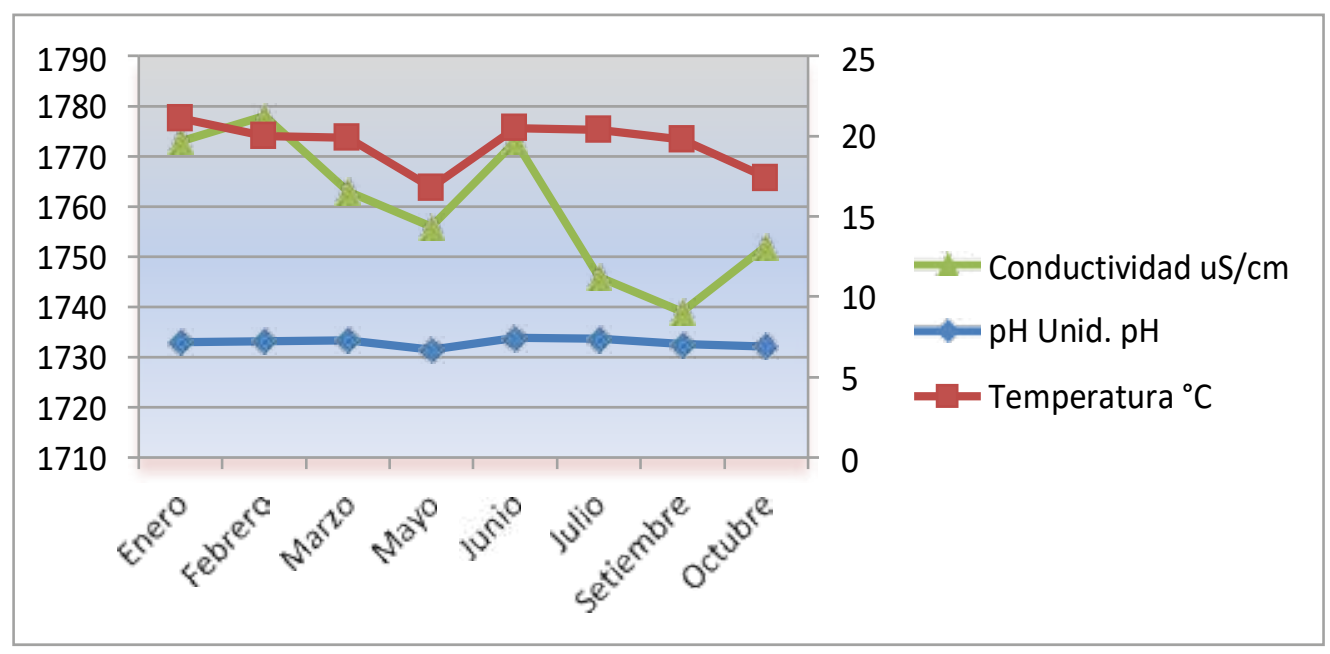

Figura 2. Parámetros de análisis de campo del agua del fundo San Bernardo

Los valores medidos de $\mathrm{pH}$ del agua de manantial del fundo San Bernardo durante las cuatro estaciones oscilan entre 6,92 - 7,30 como se muestra en la Figura 2. Estos valores están dentro de los valores dados por la norma del DS 031-2010 SA; la conductividad debe ser menor a $1500 \mathrm{uS} / \mathrm{cm}$, pero en la fuente estudiada sobrepasó este límite en todas las estaciones, dando valores de $1778 \mathrm{uS} / \mathrm{cm}$ como máximo para el muestreo de febrero del 2014 y como mínimo $1739 \mathrm{uS} / \mathrm{cm}$ para el muestreo de setiembre 2014.
En la Tabla 3 y Figura 3, se observan que el agua del fundo San Bernardo se encuentra libre de olores y sabores extrańos. La EPA y la OMS recomiendan que las fuentes de abastecimiento de agua de consumo humano deban ser razonablemente exentas de olor y de sabor aceptable. La OMS recomienda como máximo para el color 15 unidades de color. La fuente estudiada resultó con valores de cinco unidades de color que están por debajo de la norma. En cuanto a la turbidez durante las estaciones del año 2014, los valores obtenidos oscilan entre 
0,90 y 0,25 UNT. Los valores logrados de sólidos disueltos oscilan entre 1167 a $1120 \mathrm{mg} / \mathrm{L}$ de SDT que sobrepasan el límite máximo permisible de $1000 \mathrm{mg} / \mathrm{L}$ dado por la norma DS No 031-2010.

Tabla 3

Resultados de parámetros físicos del agua de manantial del fundo San Bernardo en laboratorio

\begin{tabular}{lcccccccc}
\hline & $\begin{array}{c}\text { Temp. } \\
{ }^{\circ} \mathbf{C}\end{array}$ & $\mathbf{p H}$ & $\begin{array}{c}\text { C.E. } \\
\mathbf{m g} / \mathbf{L}\end{array}$ & $\begin{array}{c}\text { Sólidos } \\
\text { disueltos } \\
\text { totales } \\
\mathbf{m g} / \mathbf{L}\end{array}$ & $\begin{array}{c}\text { Turbidez } \\
\mathbf{U N T}\end{array}$ & $\begin{array}{c}\text { Color } \\
\mathbf{U V C} \\
\text { escala } \\
\mathbf{p t / C o}\end{array}$ & $\begin{array}{c}\text { Sólidos } \\
\text { suspendidos } \\
\text { totales mg/L }\end{array}$ & $\begin{array}{c}\text { Sólidos } \\
\text { totales } \\
\mathbf{m g} / \mathbf{L}\end{array}$ \\
\hline Enero -verano & 21,1 & 7,20 & 1773 & 1167 & 0,88 & 5 & 1 & 1168 \\
Febrero- verano & 20,0 & 7,25 & 1778 & 1165 & 0,90 & 5 & 1 & 1166 \\
Marzo- otońo & 19,9 & 7,30 & 1763 & 1162 & 0,86 & 5 & 1 & 1163 \\
Mayo-otońo & 16,8 & 6,71 & 1756 & 1162 & 0,82 & 5 & 1 & 1163 \\
Junio-invierno & 20,5 & 7,45 & 1773 & 1158 & 0,70 & 5 & 1 & 1159 \\
Julio-invierno & 20,4 & 7,38 & 1746 & 1147 & 0,52 & 5 & 1 & 1148 \\
Setiembre -primavera & 19,8 & 7,06 & 1739 & 1153 & 0,26 & 5 & 1 & 1154 \\
Octubre- primavera & 17,4 & 6,92 & 1752 & 1120 & 0,25 & 5 & 1 & 1121 \\
\hline
\end{tabular}

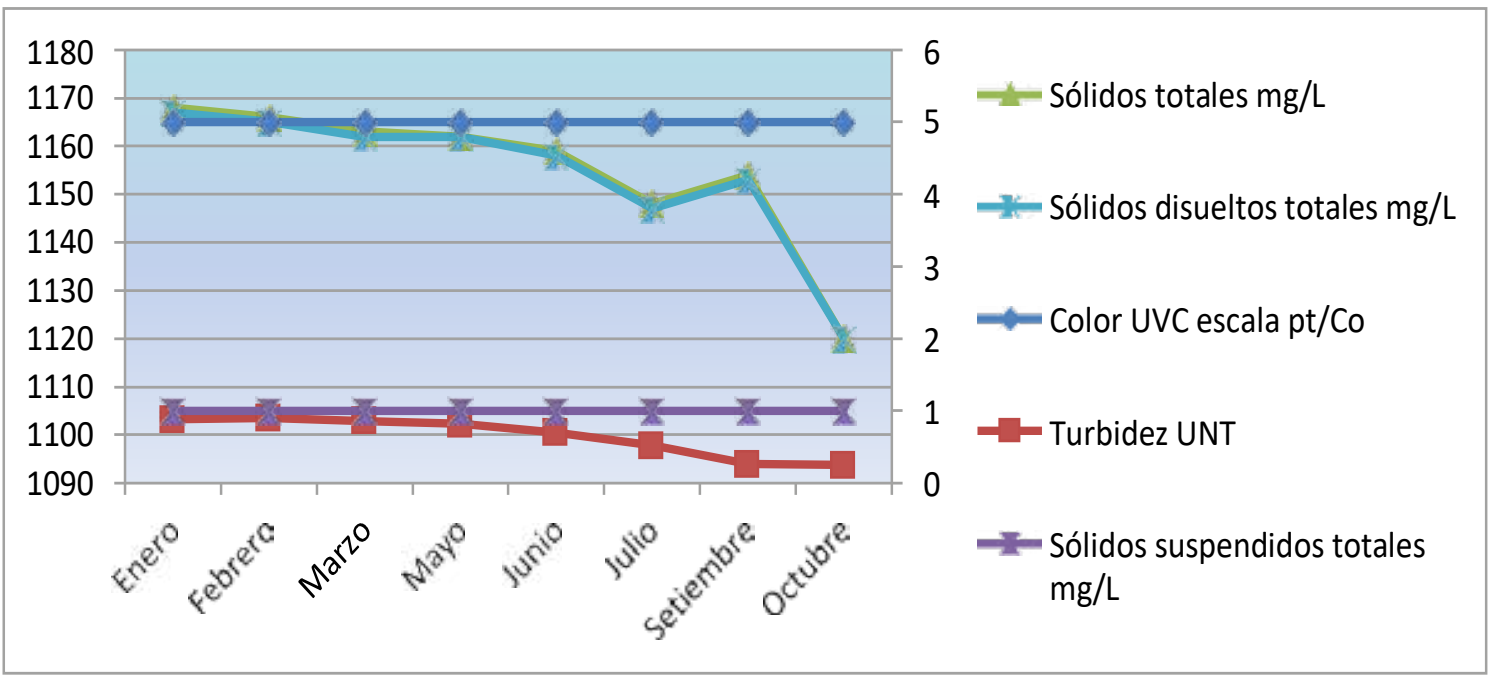

Figura 3. Análisis de parámetros físicos del agua de manantial del fundo San Bernardo

En la Tabla y Figura 4, se observan que la alcalinidad total se mantiene en valores menores a $500 \mathrm{mg} / \mathrm{L}$ de $\mathrm{CaCO} 3$, acorde al Reglamento de la Calidad del agua para consumo Humano $\mathrm{DSN}^{\circ} 031$ 2010. En la mayoría de las muestras la dureza fue mayor de $500 \mathrm{mg} / \mathrm{L}$ de $\mathrm{CaCO} 3$; sin embargo, en los meses de julio, agosto y octubre fue de 493,11
mg/L de $\mathrm{CaCO} 3,492,39$ mg/L, 491,39 $\mathrm{mg} / \mathrm{L}$ respectivamente; la dureza total es aproximadamente igual a la suma de la dureza producida por los iones calcio $y$ magnesio. Los cloruros se encuentran por encima de $250 \mathrm{mg} / \mathrm{L}$, del valor dado por la norma, en todas las muestras del año 2014. 
Tabla 4

Resultados de análisis químico del agua de manantial del fundo San Bernardo

\begin{tabular}{l|cc|cc|cc|cc}
\hline \multicolumn{1}{|c|}{ Muestreos } & \multicolumn{2}{c|}{$\begin{array}{c}\text { Estación } \\
\text { de verano 2014 }\end{array}$} & \multicolumn{2}{c|}{$\begin{array}{c}\text { Estación } \\
\text { de otono 2014 }\end{array}$} & \multicolumn{2}{c}{$\begin{array}{c}\text { Estación } \\
\text { de invierno 2014 }\end{array}$} & \multicolumn{2}{c}{$\begin{array}{c}\text { Estación de } \\
\text { primavera 2014 }\end{array}$} \\
Parámetro & Enero & Febrero & Marzo & Mayo & Junio & Julio & Setiembre & Octubre \\
\hline $\begin{array}{l}\text { Alcalinidad total } \\
\text { mg/L CaCO3 }\end{array}$ & 366,24 & 365,42 & 372,13 & 350,45 & 354,71 & 357,79 & 378,96 & 377,73 \\
$\begin{array}{l}\text { Carbonatos mg/L } \\
\text { CaCO3 }\end{array}$ & 2,5 & 2,5 & 2,5 & 2,5 & 2,5 & 2,5 & 2,5 & 2,5 \\
$\begin{array}{l}\text { Bicarbonatos } \\
\text { mg/L CaCO3 }\end{array}$ & 456,22 & 458,62 & 464,64 & 456,24 & 446,37 & 436,50 & 462,33 & 460,82 \\
$\begin{array}{l}\text { Cloruros mg/L } \\
\text { Cl- }\end{array}$ & 311,1 & 310,32 & 307,64 & 302,52 & 297,09 & 298,47 & 284,36 & 281,36 \\
$\begin{array}{l}\text { Dureza mg/L } \\
\text { CaCO3 }\end{array}$ & 524,26 & 526,64 & 523,48 & 514,59 & 521,00 & 493,11 & 492,39 & 491,39 \\
\hline
\end{tabular}

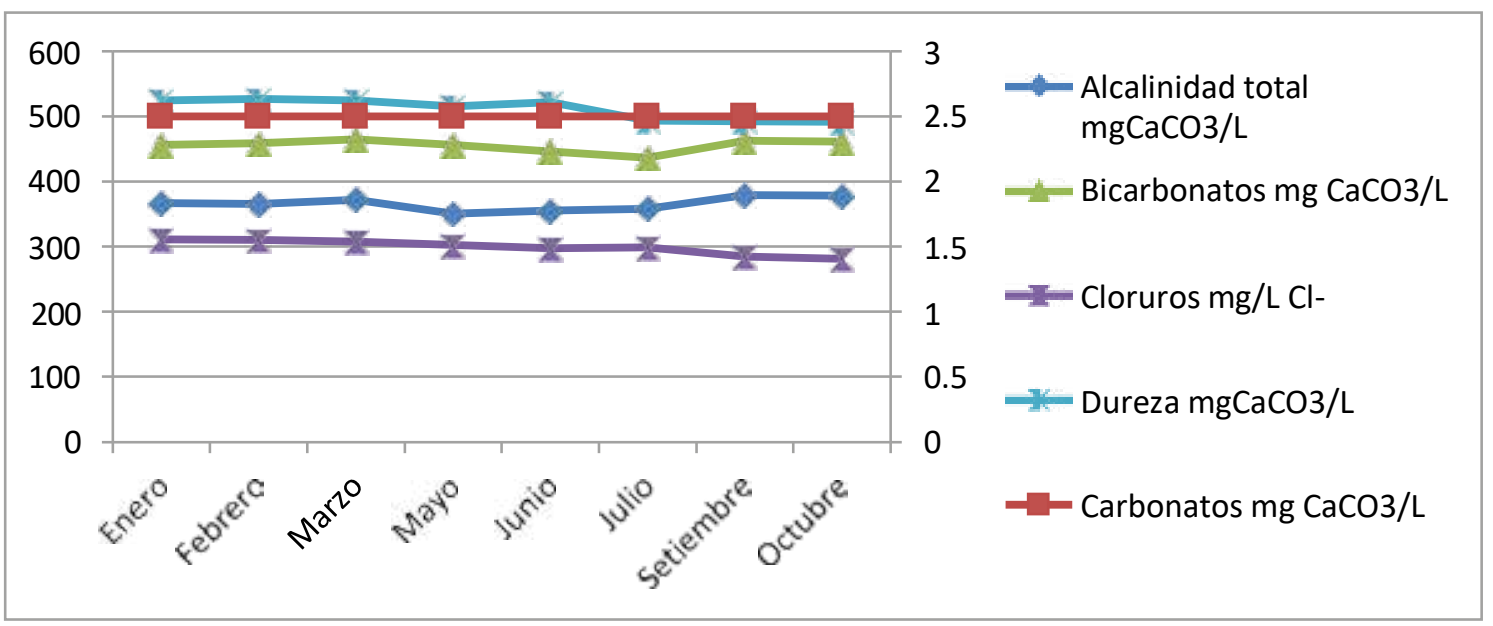

Figura 4. Análisis químico del agua de manantial del fundo San Bernardo

En la Tabla y Figura 5 se observan que el sulfato se encuentra dentro los límites máximos permisibles. La OMS y el DS $\mathrm{N}^{\circ}$ 031-2010 recomiendan que los aniones sulfato no excedan a $250 \mathrm{mg} / \mathrm{L}$ en aguas destinadas al consumo humano. Este valor está destinado a evitar la probable corrosividad del agua. El contenido detectado del anión $\mathrm{F}^{-}$fue de $1,09 \mathrm{mg} / \mathrm{L}$ para febrero y $1,07 \mathrm{mg} / \mathrm{L}$ para julio. Se mantiene casi contante el anión $\mathrm{F}^{-}$, pero para el mes de setiembre y octubre se obtuvieron los valores de 0,29 y $0,39 \mathrm{mg} / \mathrm{L}$ respectivamente. Según el reglamento de la calidad del agua para consumo humano DS $\mathrm{N}^{\circ}$ 031- 2010, los valores son 1,0 mg/L.
Según los resultados obtenidos, se observó que, para la estación de verano, otoño e invierno el anión $\mathrm{F}^{-}$sobrepasa ligeramente el límite máximo permisible, pero en primavera disminuye el anión $\mathrm{F}^{-}$ a un promedio de $0,34 \mathrm{mg} / \mathrm{L}$. Mientras que la norma europea y la Organización Panamericana de la Salud, recomiendan un límite máximo permisible para agua de consumo humano de $1,5 \mathrm{mg} / \mathrm{L}$. De acuerdo a estas normas, el agua del fundo San Bernardo estaría apta para el consumo humano.

Respecto al $\mathrm{PO} 4^{3-}$ se obtuvo $1,16 \mathrm{mg} / \mathrm{L}$ en el mes de setiembre como valor máximo 
$y$ en el mes de julio $1,00 \mathrm{mg} / \mathrm{L}$ como valor mínimo. El reglamento de la calidad del agua para consumo humano DS $\mathrm{N}^{\circ}$ 031-2010 no establece un límite máximo permisible para este parámetro. Según los estándares nacionales de calidad ambiental para agua, categoría 3 (riego de vegetales y bebidas de animales) establece un límite máximo permisible de $3.06 \mathrm{mg} / \mathrm{L}$ de anión $\mathrm{PO}_{4}^{3-}$.

El $\mathrm{NO}_{2}^{-}$se detectó en febrero una concentración de 0,006 mg/L y 0,002 $\mathrm{mg} / \mathrm{L}$ de en octubre como mínimo. En comparación a las aguas subterráneas de
La Joya (Arequipa), estas contienen un alto índice de anión $\mathrm{NO}_{2}^{-}$, este comentario es, en base a la experiencia adquirida en el laboratorio (BHIOS LABORATORIOS S.R.L). Por lo general, todas las aguas subterráneas naturales contienen concentraciones bajas de anión $\mathrm{NO}_{2}^{-}$. El reglamento de la calidad del agua para consumo humano DS $\mathrm{N}^{\circ}$ 031-2010 establece un límite máximo permisible para el anión $\mathrm{NO}^{-}$de 3,00 mg/L exposición corta y de $0,20 \mathrm{mg} / \mathrm{L}$ de ion $\mathrm{NO}_{2}^{-}$para exposición larga. En el agua del fundo San Bernardo los valores detectados son muy bajos.

\section{Tabla 5}

Resultados del análisis fisicoquímico del agua de manantial del fundo San Bernardo

\begin{tabular}{|c|c|c|c|c|c|c|c|c|}
\hline \multirow{2}{*}{ Parámetro } & \multicolumn{2}{|c|}{$\begin{array}{c}\text { Estación } \\
\text { de verano } 2014\end{array}$} & \multicolumn{2}{|c|}{$\begin{array}{c}\text { Estación } \\
\text { de otoño } 2014\end{array}$} & \multicolumn{2}{|c|}{$\begin{array}{c}\text { Estación } \\
\text { de invierno } 2014\end{array}$} & \multicolumn{2}{|c|}{$\begin{array}{c}\text { Estación de } \\
\text { primavera } 2014\end{array}$} \\
\hline & Enero & Febrero & Marzo & Mayo & Junio & Julio & Setiembre & Octubre \\
\hline $\begin{array}{l}\text { Sulfatos, } \mathrm{SO}_{4}= \\
\mathrm{mg} / \mathrm{L}\end{array}$ & 144,1 & 146,45 & 145,10 & 142,90 & 144,11 & 132,48 & 122,09 & 133,44 \\
\hline $\begin{array}{l}\text { Fluoruros, } F^{-} \\
\mathrm{mg} / \mathrm{L}\end{array}$ & 1,04 & 1,09 & 1,02 & 1,03 & 1,06 & 1,07 & 0,29 & 0,39 \\
\hline $\begin{array}{l}\text { Fosfatos, } \mathrm{PO}_{4}^{-3} \\
\mathrm{mg} / \mathrm{L}\end{array}$ & 1,11 & 1,13 & 1,10 & 1,01 & 1,03 & 1,00 & 1,16 & 1,06 \\
\hline $\begin{array}{l}\text { Nitratos } \mathrm{NO}^{-} \\
\mathrm{mg} / \mathrm{L}\end{array}$ & 0,6 & 0,7 & 0,5 & 0,6 & 0,3 & 0,6 & 0,7 & 0,7 \\
\hline $\begin{array}{l}\text { Nitritos, } \mathrm{NO}_{2}^{-} \\
\mathrm{mg} / \mathrm{L}\end{array}$ & 0,005 & 0,006 & 0,004 & 0,005 & 0,004 & 0,002 & 0,004 & 0,002 \\
\hline $\begin{array}{l}\text { Boro, B } \\
\mathrm{mg} / \mathrm{L}\end{array}$ & 5,1 & 5,4 & 4,9 & 5,3 & 4,7 & 5,0 & 6,0 & 5,4 \\
\hline $\begin{array}{l}\text { Dióxido de } \\
\text { silicio(SiO2) mg/L }\end{array}$ & 28,22 & 29,48 & 27,78 & 25,68 & 24,68 & 23,78 & 21,50 & 14,55 \\
\hline $\begin{array}{l}\mathrm{NH} 3-\mathrm{H}, \\
\text { amoniaco mg/L }\end{array}$ & 0,07 & 0,08 & 0,05 & 0,06 & 0,07 & $\mathrm{ND}^{*}$ & 0,04 & ND \\
\hline
\end{tabular}

$\mathrm{ND}^{*}=$ No Detectado

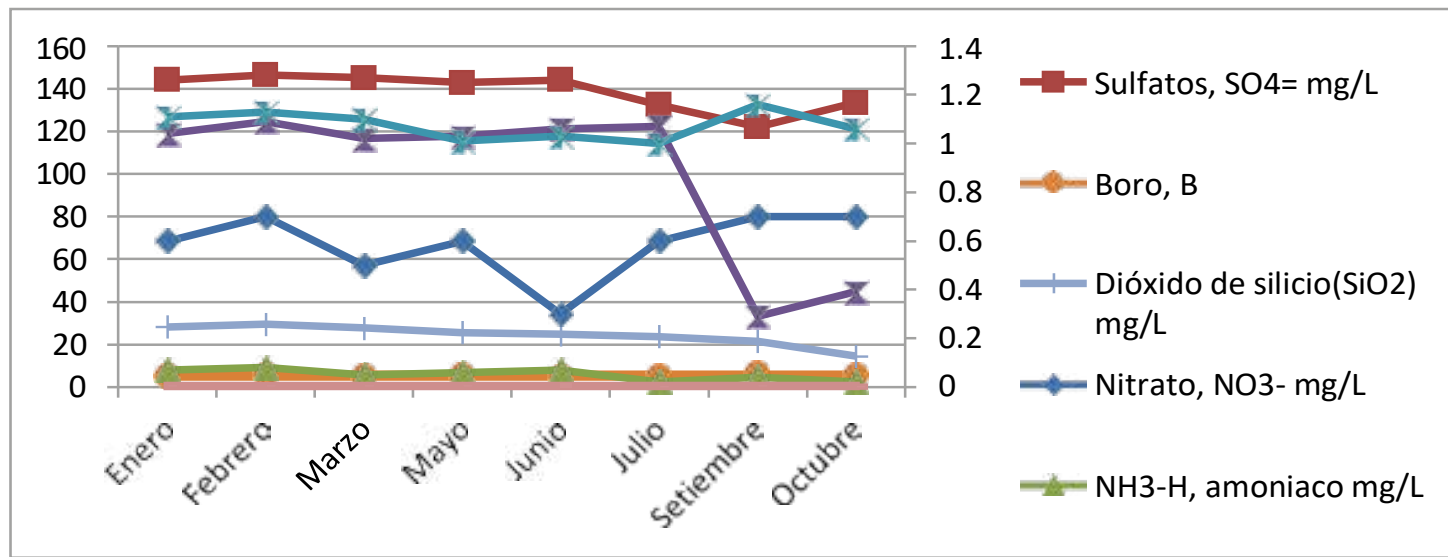

Figura 5. Análisis fisicoquímico del agua de manantial del fundo San Bernardo 
En cuanto al amoniaco, la fuente estudiada registró valores mínimos para los meses de enero, febrero, marzo, mayo, junio y setiembre mientras que para julio y octubre no fue detectado. El DSN 031 2010 recomienda un límite máximo permisible para agua de consumo humano de 1,5 mg/L de NH3.

En la Tabla y Figura 5, se encontró $6 \mathrm{mg} / \mathrm{L}$ de boro en el mes de setiembre como máximo y $4,7 \mathrm{mg} / \mathrm{L}$ en junio como mínimo. El reglamento de la calidad del agua para consumo humano $\mathrm{DSN}^{\circ} 031$ 2010 establece como límite máximo permisible de $1,5 \mathrm{mg} / \mathrm{L}$ de boro. El agua del fundo San Bernardo excede los estándares de calidad para el agua de consumo humano, en todas las estaciones del año 2014. La OMS ha establecido como valor guía para aguas de consumo $0,3 \mathrm{mg} / \mathrm{L}$, mientras en Canadá considera $5 \mathrm{mg} / \mathrm{L}$ como concentración máxima aceptable, y para aguas minerales de bebida la NTP fija una concentración máxima permisible de $30 \mathrm{mg} / \mathrm{L} \mathrm{H} 3 \mathrm{BO} 3$ (21,3 mg/L HBO2).

En la Tabla y Figura 6 se puede observar que la concentración máxima del $\mathrm{Ca}^{2+}$ fue de $111,12 \mathrm{mg} / \mathrm{L}$ en el mes de febrero y $95,78 \mathrm{mg} / \mathrm{L}$ para el mes de julio como mínimo. En cuanto al catión magnesio se obtuvo 61,66 mg/L de $\mathrm{Mg}^{2+}$ en julio como máximo y $58,28 \mathrm{mg} / \mathrm{L}$ de $\mathrm{Mg}^{2+}$ como mínimo en setiembre. Las aguas dulces suelen contener de 10 a $250 \mathrm{mg} / \mathrm{L}$ de $\mathrm{Ca}^{2+}$, o incluso $600 \mathrm{mg} / \mathrm{L}$ de catión $\mathrm{Ca}^{2+}$, el agua de mar contiene $400 \mathrm{mg} / \mathrm{L}$ de $\mathrm{Ca}^{2+}$, mientras que en terrenos yesíferos pueden llegar a 600 $\mathrm{mg} / \mathrm{L}$ de catión $\mathrm{Ca}^{2+}$. Rigola (1999). En la fuente en estudio la concentración de catión $\mathrm{Ca}^{2+}$ fue constante en los cinco muestreos del año 2014 (enero, febrero, marzo, mayo, junio,) y disminuye en 10 $\mathrm{mg} / \mathrm{L}$ para el mes de julio. El reglamento de la calidad del agua para consumo humano DS $\mathrm{N}^{\circ}$ 031-2010 no establece el límite máximo permisible para los cationes $\mathrm{Ca}^{2+} \mathrm{y} \mathrm{Mg}^{2+}$.

En cuanto a los cationes, sodio y potasio se obtuvo $240,64 \mathrm{mg} / \mathrm{L}$ de $\mathrm{Na}^{+}$ como máximo en el mes de febrero y 177,27 mg/L como mínimo en el mes de setiembre, este catión se encontró en mayor cantidad. Respecto al $\mathrm{K}^{+}$se encontró $22,82 \mathrm{mg} / \mathrm{L}$ de como máximo en el mes de febrero y $17,26 \mathrm{mg} / \mathrm{L}$ de como mínimo en el mes de setiembre. La concentración del $\mathrm{Na}^{+}$en aguas naturales es muy variable, pudiendo alcanzar hasta $120,000 \mathrm{mg} / \mathrm{L}$ en zonas evaporíticas; sin embargo, en aguas dulces normales, raramente sobrepasa 100 o $150 \mathrm{mg} / \mathrm{L}$, Rigola, (1999). Respecto al arsénico, este es muy dañino para la salud humana, en el estudio del agua del fundo San Bernardo se encontró en los rangos de 0,25 a $0,36 \mathrm{mg} / \mathrm{L}$ sobrepasando los estándares de calidad del agua del DS $\mathrm{N}^{\circ}$ 004- 2017-MINAN y $\mathrm{DSN}^{\circ} 031-2010$ que fijaron como valor máximo de 0,010 $\mathrm{mg} / \mathrm{L}$. 
Tabla 6

Resultados de análisis de metales por absorción atómica del agua de manantial del fundo San Bernardo

\begin{tabular}{|c|c|c|c|c|c|c|c|c|}
\hline \multirow[b]{2}{*}{ Parámetro } & \multicolumn{2}{|c|}{$\begin{array}{c}\text { Estación de verano } \\
2014\end{array}$} & \multicolumn{2}{|c|}{$\begin{array}{c}\text { Estación de otoño } \\
2014\end{array}$} & \multicolumn{2}{|c|}{$\begin{array}{c}\text { Estación de invierno } \\
2014\end{array}$} & \multicolumn{2}{|c|}{$\begin{array}{c}\text { Estación de primavera } \\
\qquad 2014\end{array}$} \\
\hline & Enero & Febrero & Marzo & Mayo & Junio & Julio & Setiembre & Octubre \\
\hline Calcio, Ca mg/L & 110,86 & 111,12 & 109,26 & 108,57 & 110,51 & 95,78 & 101,08 & 99,81 \\
\hline $\begin{array}{l}\text { Magnesio, } \mathrm{Mg} \\
\mathrm{mg} / \mathrm{L}\end{array}$ & 60,52 & 60,47 & 60,86 & 59,05 & 59,49 & 61,66 & 58,28 & 58,81 \\
\hline Sodio, Na mg/L & 240,22 & 240,64 & 237,10 & 230,85 & 183,88 & 175,99 & 177,27 & 177,54 \\
\hline Potasio, K mg/L & 22,6 & 22,82 & 21,10 & 20,22 & 18,54 & 18,84 & 17,26 & 18,18 \\
\hline $\begin{array}{l}\text { Manganeso, Mn } \\
\mathrm{mg} / \mathrm{L}\end{array}$ & 0,14 & 0,15 & 0,13 & 0,12 & 0,10 & 0,14 & 0,04 & 0,04 \\
\hline $\begin{array}{l}\text { Arsénico, As } \\
\mathrm{mg} / \mathrm{L}\end{array}$ & 0,032 & 0,033 & 0,029 & 0,025 & 0,036 & 0,027 & 0,034 & 0,032 \\
\hline
\end{tabular}

Figura 6. Parámetros químicos del agua del fundo San Bernardo

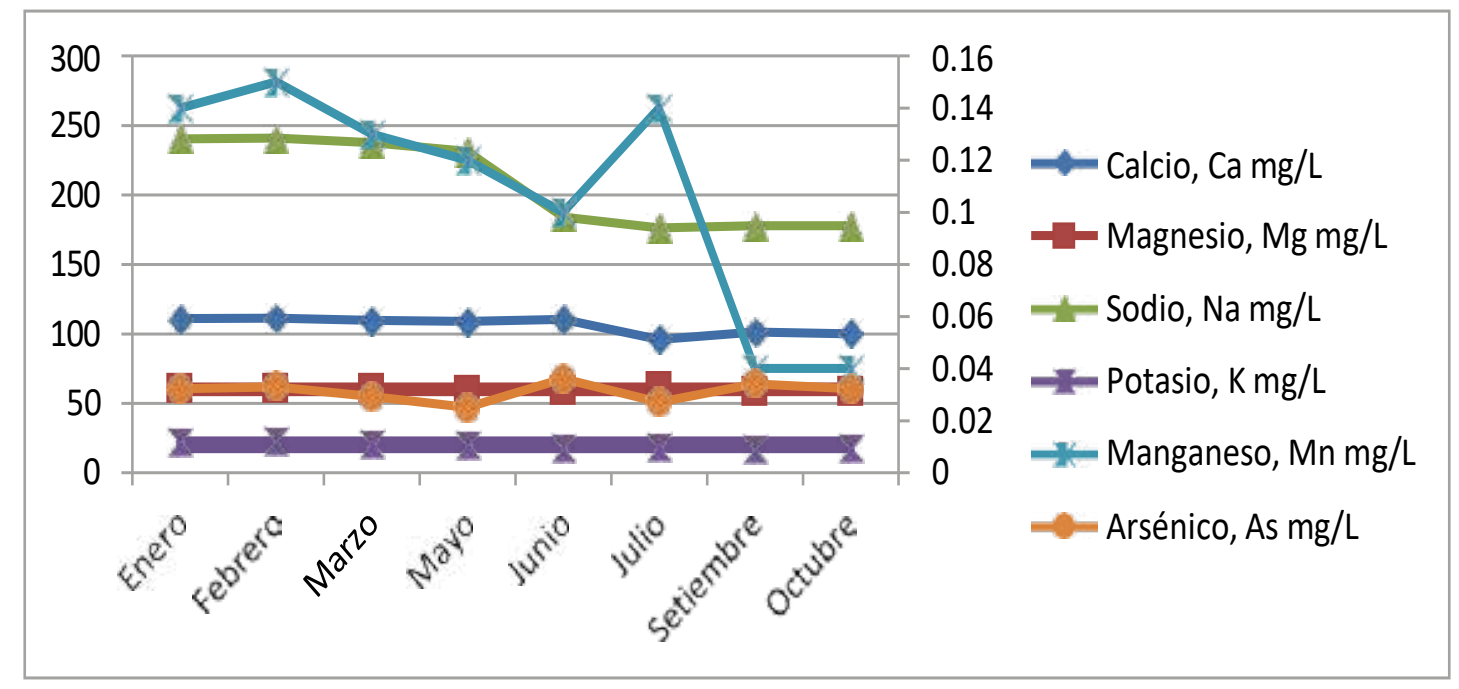

Los elementos ecotóxicos $\mathrm{Cu}, \mathrm{Pb}, \mathrm{Fe}$, Mn por el método de absorción atómica dieron valores muy bajos en todas las muestras considerando que en el mes de octubre la concentración de los metales fue mayor en tres muestras. Razón por la cual, se hizo una corrida de ellas por ICP-MS (espectrofotometría de emisión plasma acoplado inductivamente a masas, Tabla 7). 
Tabla 7

Elementos ecotóxicos por ICP-masas

\begin{tabular}{|c|c|c|c|c|}
\hline \multicolumn{5}{|c|}{ ESTACIÓN DE PRIMAVERA ( MES DE OCTUBRE 28-10-2014) } \\
\hline DA D ́́ METDOY UTUDA & Límite de detección & Muestra 1 & Muestra 2 & Muestra 3 \\
\hline & 0,00200 & $<0,00200$ & $<0,00200$ & $<0,00200$ \\
\hline Aluminio, $\mathrm{Al}-\mathrm{mg} / \mathrm{L} *$ & 0,00400 & 0,01800 & 0,01900 & 0,02200 \\
\hline Arsénico, As -mg/L * & 0,00400 & 0,03200 & 0,04100 & 0,03900 \\
\hline Boro, B- $\mathrm{mg} / \mathrm{L} \quad *$ & 0,00200 & 5,18700 & 5,24100 & 5,27800 \\
\hline Bario, Ba- mg/L * & 0,00050 & 0,06110 & 0,06060 & 0,06090 \\
\hline Berilio, Be- mg/L & 0,00002 & $<0,00002$ & $<0,00002$ & $<0,00002$ \\
\hline Bismuto, Bi -mg/L & 0,00200 & $<0,00200$ & $<0,00200$ & $<0,00200$ \\
\hline Calcio, $\mathrm{Ca}-\mathrm{mg} / \mathrm{L} \quad *$ & 0,02000 & 94,90000 & 93,70000 & 94,40000 \\
\hline Cadmio, Cd -mg/L & 0,00030 & $<0,00030$ & $<0,00030$ & $<0,00030$ \\
\hline Cobalto, Co -mg/L & 0,00070 & $<0,00070$ & $<0,00070$ & $<0,00070$ \\
\hline Cromo, $\mathrm{Cr}-\mathrm{mg} / \mathrm{L}$ & 0,00080 & $<0,00080$ & $<0,00080$ & $<0,00080$ \\
\hline Cobre, $\mathrm{Cu}-\mathrm{mg} / \mathrm{L}$ & 0,00200 & $<0,00200$ & $<0,00200$ & $<0,00200$ \\
\hline Hierro, Fe -mg/L & 0,00600 & $<0,00600$ & $<0,00600$ & $<0,00600$ \\
\hline Potasio, $\mathrm{K}-\mathrm{mg} / \mathrm{L} \quad *$ & 0,05000 & 24,47000 & 24,39000 & 24,42000 \\
\hline Litio, Li -mg/L & 0,00800 & 0,39400 & 0,39500 & 0,39600 \\
\hline Magnesio, $-\mathrm{Mg} \mathrm{mg} / \mathrm{L}^{*}$ & 0,00800 & 58,54800 & 58,00000 & 58,07000 \\
\hline Manganeso,- $\mathrm{Mn} \mathrm{mg} / \mathrm{L}^{* *}$ & 0,00300 & 0,05100 & 0,05300 & 0,05100 \\
\hline Molibdeno, Mo- mg/L & 0,00090 & $<0,00090$ & $<0,00090$ & $<0,00090$ \\
\hline Sodio, $\mathrm{Na}-\mathrm{mg} / \mathrm{L} \quad *$ & 0,02000 & 145,05000 & 147,31000 & 150,97000 \\
\hline Níquel, Ni -mg/L & 0,00200 & 0,04100 & 0,04200 & 0,04000 \\
\hline Fósforo, $\mathrm{P}$-mg/L & 0,00300 & 0,22800 & 0,21400 & 0,22700 \\
\hline Plomo, $\mathrm{Pb}-\mathrm{mg} / \mathrm{L}^{* *}$ & 0,00400 & $<0,00400$ & $<0,00400$ & $<0,00400$ \\
\hline Antimonio, $\mathrm{Sb}-\mathrm{mg} / \mathrm{L}$ & 0,00300 & $<0,00300$ & $<0,00300$ & $<0,00300$ \\
\hline Selenio, Se -mg/L & 0,00600 & $<0,00600$ & $<0,00600$ & $<0,00600$ \\
\hline Silicio, Si -mg/L & 0,00400 & 41,05000 & 40,50000 & 40,58200 \\
\hline Estaño, Sn -mg/L & 0,00070 & $<0,00070$ & $<0,00070$ & $<0,00070$ \\
\hline Estroncio, $\mathrm{Sr}-\mathrm{mg} / \mathrm{L}$ & 0,00050 & 1,05290 & 1,04830 & 1,04730 \\
\hline Titanio, Ti -mg/L & 0,00070 & $<0,00070$ & $<0,00070$ & $<0,00070$ \\
\hline Talio, Tl -mg/L & 0,00300 & $<0,00300$ & $<0,00300$ & $<0,00300$ \\
\hline Vanadio, V -mg/L & 0,00200 & 0,01000 & 0,00900 & 0,01000 \\
\hline Zinc , Zn -mg/L & 0,00070 & $<0,00070$ & $<0,00070$ & $<0,00070$ \\
\hline
\end{tabular}

En la Tabla 7 se realizó una corrida de tres muestras, del mes de octubre por el método ICP-MS (espectrofotometría de emisión plasma acoplado inductivamente a masas). Se observó que los elementos ecotóxicos $\mathrm{Cu}, \mathrm{Pb}, \mathrm{Fe}, \mathrm{Mn},\left({ }^{* *}\right)$ también presentaron valores bajos, casi similares a los valores obtenidos por el método de absorción atómica. Mientras que los elementos: $\mathrm{Al}, \mathrm{As}, \mathrm{B}, \mathrm{Ca}, \mathrm{K}, \mathrm{Mg}, \mathrm{Na}$, $\mathrm{Si},\left(^{*}\right)$ presentaron valores significativos. Medina, L. (2015). 
En la Tabla 8 de análisis microbiológico y su evaluación del agua del manantial del fundo San Bernardo, se observó que en el recuento de Microorganismos Heterótrofos (UFC/ $\mathrm{mL}$ ) se encontró 980, y la norma indica 500 como límite máximo permisible; por tanto, no cumple, para el uso de bebida de consumo humano. En el muestro se encontró algas verdes, en gran cantidad, que son frecuentes en los reservorios de agua. Quinteros-Herrera (2009). En cuanto a Numeración de Coliformes totales se obtuvo 240 $\mathrm{NMP} / 100 \mathrm{~mL}$ y de Escherichia coli $240 \mathrm{NMP} / 100 \mathrm{~mL}$, ambos valores se encuentran que no cumplen con los requisitos de la norma.

Tabla 8

Análisis microbiológico y su evaluación

\begin{tabular}{|c|c|c|c|c|c|c|c|}
\hline DETERMINACIÓN & 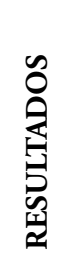 & $\begin{array}{l}\text { PERMISIBLE } \\
\text { Aguas que } \\
\text { pueden ser } \\
\text { potabilizadas } \\
\text { con } \\
\text { desinfección } \\
\text { (A1) }\end{array}$ & 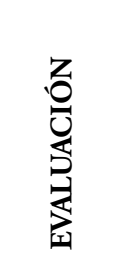 & $\begin{array}{l}\text { PERMISIBLE } \\
\text { Aguas que } \\
\text { pueden } \\
\text { ser potabilizadas } \\
\text { con tratamiento } \\
\text { convencional } \\
\text { (A2) }\end{array}$ & 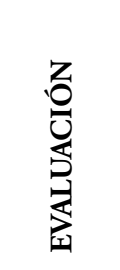 & $\begin{array}{l}\text { PERMISIBLE } \\
\text { Aguas que } \\
\text { pueden } \\
\text { ser potabilizadas } \\
\text { con tratamiento } \\
\text { avanzado (A3) }\end{array}$ & 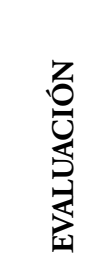 \\
\hline $\begin{array}{l}\text { Bacterias Coliformes } \\
\text { Totales } \\
(\mathrm{NMP} / 100 \mathrm{~mL})\end{array}$ & 240 & 50 & $\begin{array}{c}\text { No } \\
\text { Cumple }\end{array}$ & -- & -- & -- & -- \\
\hline $\begin{array}{l}\text { Recuento de } \\
\text { Microorganismos } \\
\text { Heterótrofos } \\
\text { (UFC/mL) }\end{array}$ & 980 & 500 & $\begin{array}{c}\text { No } \\
\text { Cumple }\end{array}$ & -- & -- & -- & -- \\
\hline $\begin{array}{l}\text { Bacterias Coliformes } \\
\text { Termo-Tolerantes o } \\
\text { Fecales (NMP/100 L) } \\
\text { a } 44^{\circ} \mathrm{C}\end{array}$ & 240 & 20 & $\begin{array}{c}\text { No } \\
\text { Cumple }\end{array}$ & 2000 & Cumple & 20000 & Cumple \\
\hline
\end{tabular}

- TaUFC/mL: Unidades formadoras de colonias por mililitro de muestra

- NMP/100mL: Número más probable por 100 mililitros de muestra

\section{Conclusiones}

Se determinaron los parámetros físicos, químicos, aniones y cationes: La concentración de hidrógeno estuvo entre 6,71 a 7,45, laconductividad eléctrica entre $1778 \mu \mathrm{S} / \mathrm{cm}$ y $1739 \mu \mathrm{S} / \mathrm{cm}$ en setiembre. La dureza total entre $526,64 \mathrm{mg} / \mathrm{L}$ y $491,39 \mathrm{mg} / \mathrm{L}$. Los aniones: $\mathrm{Cl}^{-}, \mathrm{F}^{-}, \mathrm{SO}_{4}{ }^{2-}$ , $\mathrm{NO}_{2}^{-}$, presentaron una concentración mayor en verano y menor en primavera. La concentración de aniones: $\mathrm{NO}^{-}, \mathrm{PO}_{4}^{3-}$ fue mayor en verano y menor en invierno. La concentración de cationes: $\mathrm{Na}^{+}, \mathrm{K}^{+}$, $\mathrm{Ca}^{2+}$ fue mayor en verano y menor en invierno. Mientras que el catión $\mathrm{Mg}^{2+}$ estuvo en $61,66 \mathrm{mg} / \mathrm{L}$ en julio y 58,28 $\mathrm{mg} / \mathrm{L}$ en setiembre. Se establecieron los elementos ecoecotóxicos (arsénico, bario, boro, cadmio, cromo, plomo, mercurio, selenio y anión cianuro). El catión $\mathrm{As}^{3+}$ presentó una concentración de 0,036 $\mathrm{mg} / \mathrm{L}$ en junio y $0,025 \mathrm{mg} / \mathrm{L}$ de ion $\mathrm{As}^{3+}$ en mayo. Los elementos ecotóxicos: $\mathrm{Cr}$, $\mathrm{Pb}, \mathrm{Hg}, \mathrm{Mo} \mathrm{y} \mathrm{CN}^{-}$no fueron detectados. El catión $\mathrm{Mn}^{2+}$ estuvo entre los valores dados por la norma. En cuanto a los parámetros microbiológicos (coliformes totales y fecales). Los resultados fueron comparados con el DS $\mathrm{N}^{\circ}$ 031-2010 y la NTP 214. 024- 1988 (Revisada y publicada No 031-2017 -INACAL / 
DN (2017-09-05). Se concluye que el $\mathrm{pH}$ está dentro de la norma. La dureza total, sólidos disueltos y la conductividad eléctrica, exceden el LMP del DSN $031-$ 2010. Los iones $\mathrm{As}^{3+}, \mathrm{F}^{-}, \mathrm{Cl}^{-}$y el boro exceden al valor dado en el $\mathrm{DSN}^{\circ} 031$ -
2010-SA. Según Rigola esta agua subterránea es muy dura, pertenece a una clase de tipo mineral, por el grado de mineralización, según el residuo seco a $180^{\circ} \mathrm{C}$. Por tanto, podría ser utilizada solo para riego.

\section{Referencias}

Masías, P. (2007). Estudios geoquímicos de las fuentes termales y frías asociadas al volcán Misti. (Tesis de Licenciamiento). UNSA, FCNF (Escuela Profesional de Química), Arequipa, Perú.

Quinteros, R.-Herrera, V. (2009). Evaluación de la calidad microbiológica y fisicoquímica de aguas subterráneas ubicadas en los municipios de la Paz y San Diego, Cesar. Colombia.

Rigola, M. (1999). Tratamiento de aguas industriales: aguas de procesos $\mathrm{y}$ residuales: Barcelona: Alfaomega.
Yupanqui, E. (2006). Análisis Fisicoquímico de Fuentes de Aguas Termo minerales del Callejón de Huaylas. (Magister en química). Pontifica Universidad Católica del Perú, Lima, Perú.

Zúñiga. S. (2013). Caracterización Físicoquímica y Bacteriológica de la Fuente de agua del Ojo del Milagro deldistrito deCharacato-Arequipa. (Tesis de Licenciamiento). UNSA, FCNF (Escuela Profesional de Química), Arequipa, Perú. 
